\section{Acute care for stunned myocardium after lightning strike is life-saving: need for public awareness programs}

\author{
Ahmed Armin, ${ }^{1}$ Azim Afzal, ${ }^{1}$ \\ Singh Narayan Upendra, ${ }^{2}$ Gurjar Mohan' \\ 'Department of Critical Care Medicine, \\ Sanjay Gandhi Postgraduate Institute of \\ Medical Sciences, Lucknow; ${ }^{2}$ Department \\ of Cardiology, Sanjay Gandhi \\ Postgraduate Institute of Medical \\ Sciences, Lucknow, India
}

\section{Abstract}

Lightning injury is a global public health problem. It still exists as a major environmental threat in developing nations where majority of population lives in rural areas. The different mechanisms of lightning injury can result in a spectrum of injuries ranging from minor, through moderate to severe. The most common cause of death due to lightning strike is cardiopulmonary arrest. Prognosis and outcome in moderate to severe lightning injury depends on timing of cardiopulmonary resuscitation and specialized care to prevent anoxic injury to vital organs. India lags behind in public education, awareness programs and health resources and has the biggest number of reported deaths due to lightning injuries.

In this report, the authors highlight the importance of early cardiopulmonary support to a victim of direct lightning strike, which saved his life, and lay emphasis on the need to develop public awareness programs.

\section{Introduction}

Lightning injury is an under-reported phenomenon in many developing countries including India due to lack of provision for specific registration of deaths caused by lightning injuries. Though there is no audit, even discharge records of hospitalized patients fail to mention lightning injury as a cause of death. Therefore, although it is a public health problem, its incidence remains unknown. ${ }^{1,2}$ According to the National Crime Record Bureau of India in the year 2001 there were 1507 deaths related to lightning injury.

Lightning injury can be fatal due to cardiac and neurological insult. ${ }^{3,4}$ Acute care, resuscitation knowledge and awareness of bystanders can be life-saving because of the reversible nature of the injuries. ${ }^{5}$ We report a case of a victim of lightning injury who survived thanks to the availability of acute care facilities. To the best of our knowledge, there are currently no national programs to spread awareness regarding lightning injuries and resuscitation for general public.

\section{Case Report}

In the early hours of the morning, a thirty five year-old male with no comorbid illness was directly struck by lightning while he was going towards the farm. The patient immediately fell and became unconscious. He was rushed to private hospital by bystanders in around 30 min. On admission to hospital, he was tachypneic with a respiratory rate of $40 / \mathrm{min}$, heart rate was $130 /$ min sinus rhythm and he was sweating. There was also an entry wound near the epigastrium around $15 \mathrm{~cm}$ in diameter and involving superficial skin only. The exit wound was on the nape. The chest was full of bilateral crepts. Electrocardiography (ECG) showed sinus tachycardia without signs of injury or ischemia. Arterial blood gas showed pH -7.37, $\mathrm{PaO}_{2}-43 \mathrm{mmHg}, \mathrm{PaCO}_{2} 33.8 \mathrm{mmHg}, \mathrm{HCO}_{3}$ 19.1, $\mathrm{BE} \quad-5.3, \quad \mathrm{Na}-135 \mathrm{meq} / \mathrm{L}$ (normal-135145meq/L), K- 2.77 meqL (normal-3.5$4.5 \mathrm{meq} / \mathrm{L})$. The patient was intubated and started on mechanical ventilation. Initial laboratory workup showed a raised total leukocyte count (TLC) 24,300/cu mm (normal 411,000/cu mm), Hemoglobin (Hb) $13 \mathrm{gm} / \mathrm{dL}$ (normal $12-15 \mathrm{gm} / \mathrm{dL}$ ), platelet of $0.22 \mathrm{mil}-$ lions/cu mm (normal 0.15-0.45 millions/cu $\mathrm{mm}$ ) with normal hepatic and renal function. Chest $\mathrm{x}$ ray suggested the presence of pulmonary edema. Echocardiography (ECHO) showed a dilated left ventricle and left atrium with global hypokinesia with ejection fraction (EF) of 20\% (normal >55\%). Right ventricle showed normal size and contraction. The patient started a treatment of intravenous antibiotic piperacillin/tazobactum 4.5 g every 6 hours, injection furosemide $20 \mathrm{mg}$ every 6 hours and dobutamine (2.5-7.5 $\mu \mathrm{g} / \mathrm{kg} / \mathrm{min})$. Over the next few hours, the patient developed hypotension, which required dopamine support, and was referred to our center for further management.

At the time of admission, the patient was sedated with midazolam and paralyzed with vecuronium infusion. Pupils were normal sized with normal reaction. His pulse was $98 / \mathrm{min}$, blood pressure (BP) $120 / 70 \mathrm{mmHg}$ with dopamine support of $5 \mu \mathrm{g} / \mathrm{kg} / \mathrm{min}$. Bilateral air entry was equal with few basal crepts. His urine output was $1-2 \mathrm{~mL} / \mathrm{kg} / \mathrm{hour}$. Electrocardiography showed a $\mathrm{T}$ wave inversion and ST segment depression in all leads. Cardiac enzymes were mildly elevated [creatine phosphokinase (CPK)-total 270 units/L (normal 40-120 units)], CPK-MB 18 ng/mL
Correspondence: Afzal Azim, Department of Critical Care Medicine, Sanjay Gandhi Postgraduate Institute of Medical Sciences, Raebareli road, 226014 Lucknow, India.

Tel/Fax: +91.0522.2668017.

E-mail: afzala@sgpgi.ac.in/draazim2002@gmail.com

Key words: lightning, stunned myocardium, acute care, awareness program.

Contributions: the authors contributed equally.

Conflict of interests: the authors declare no potential conflict of interests.

Received for publication: 12 December 2012. Revision received: 15 February 2013.

Accepted for publication: 16 February 2013.

This work is licensed under a Creative Commons Attribution 3.0 License (by-nc 3.0).

(C) Copyright A. Armin et al., 2013

Licensee PAGEPress, Italy

Healthcare in Low-resource Settings 2013; 1:e11 doi:10.4081/hls.2013.e11

(normal value $0-3 \mathrm{ng} / \mathrm{mL}$ ), troponin I $0.7 \mathrm{ng} / \mathrm{mL}$ [normal value $<0.4 \mathrm{ng} / \mathrm{mL}$ ]). Supportive care

in the form of enteral nutrition, deep vein thrombosis prophylaxis, and wound care was continued. Within $24 \mathrm{~h}$, he could open his eyes, follow commands and move his limbs. There was no neurological deficit. Dobutamine was gradually tapered off in the next $48 \mathrm{~h}$. Serial ECGs showed non-specific $\mathrm{T}$ wave inversion and ST segment depression in all leads. Repeat ECHO on day 4 showed mildly dilated left ventricle with severe left ventricle dysfunction (EF $30 \%)$. A brief T piece trial was given and the patient was extubated. Post-extubation patient was conscious, oriented, following commands, and hemodynamically stable with normal urine output. Specific cardiac medications were added and included angiotensin-convertingenzyme (ACE) inhibitors (ramipril $2.5 \mathrm{mg}$ ) and beta blocker (metoprolol $25 \mathrm{mg}$ ). The patient was discharged on day 7 and was kept on follow up. Repeat ECHO was done on day 30 and showed improving cardiac parameters. Serial ECHO findings are reported in Table 1. The patient gave his informed consent.

\section{Discussion}

There are three types of lightning injuries: direct, indirect and side splash. ${ }^{1}$ Direct strike results in extensive injuries. ${ }^{1,2}$ Though multiple systems can be involved, fatal injury mostly occurs due to myocardial and neurological insult. ${ }^{1,2}$ Our patient suffered from direct cardiac injury, but did not suffer any neurological 
Table 1. Serial echocardiography findings.

\begin{tabular}{lcccccc} 
Days of injury & IVS/Pw & EDV $(\mathbf{m L})$ & ESV $(\mathbf{m L})$ & EF (\%) & $\begin{array}{c}\text { LVIDD } \\
(\mathbf{m m})\end{array}$ & $\begin{array}{c}\text { LVIDS } \\
(\mathbf{m m})\end{array}$ \\
Day 4 & $11 / 11$ & 103 & 69 & 30 & 53 & 40 \\
Day 7 & $11 / 10$ & 94 & 54.5 & 42 & 50 & 37 \\
\hline Day 30 & $9 / 9$ & 81 & 36 & 56 & 44 & 29 \\
\hline
\end{tabular}

IVS/Pw, inter ventricular septum/posterior wall; EDV, end diastolic volume; ESV, end systolic volume; EF, ejection fraction; LVIDD, left ventricle internal diameter diastole; LVIDS, left ventricle internal diameter systole.

injury. Indirect injury denotes contact of a person with a lightning struck object and side splash occurs when lightning jumps from its primary strike site to hit a nearby person or any other object in its path.

Lightning can lead to mechanical and/or electrical abnormalities in the myocardium. ${ }^{3}$ Mortality rate is around $30 \%$ with severe cardiac injury due to primary ventricular fibrillation or asystole. Therefore, emergency care especially knowledge about basic life support (BLS) regarding cardiopulmonary resuscitation (CPR) on the part of bystanders - can be life-saving. ${ }^{5}$ Our patient fortunately did not need resuscitation at the time of injury or during the transport. Moreover, none of the bystanders who transported the patient had any knowledge of CPR and they did not perform it.

Electrocardiography changes reported in the literature include sinus tachycardia, non-specific ST-T changes, temporary prolongation of QT interval and broadening of $\mathrm{T}$ wave.,7 Generally, ECG abnormalities return to normal within one month. Our patient's ECG findings included non-specific ST segment and T wave changes which reversed after 3 weeks.

Mechanical injury to heart includes myocardial stunning, infarction, pericarditis and takotsubo cardiomyopathy. ${ }^{7}$ Pathophysiology behind myocardial stunning is unclear. ${ }^{8}$ Some reports in the literature show takatsubo- shaped hypokinesia. The mechanism proposed is high catecholaminergic surge with pathogenesis still remaining controversial.

The recovery of myocardium stunned by lightning is similar to recoveries of myocardium stunned by other causes. There is a limited number of case reports in the literature discussing the recovery course of myocardium. The most comprehensive study is by Lichtenberg et al. on 19 victims in 5 separate lightning strikes over a 2 month span. ${ }^{9}$ In their study, cardiac dysfunction recovered within two weeks even in patients with biventricular failure. Our patient went into cardiogenic shock within few hours of injury requiring mechanical ventilation and inotropic support. Serial ECHO suggested recovery of cardiac parameters at around four weeks. Lightninginduced takotsubo-shaped left ventricular dysfunction is also reported to recover in 10 to 14 days. $^{9-11}$

\section{Conclusions}

Early aggressive respiratory and cardiac support (i.e. CPR) therapy can be life-saving in lightning injuries. The reversible nature of cardiac insults stresses the need to develop awareness and teaching programs related to CPR for the general public.

\section{References}

1. Holle RL. Annual rates of lightning fatalities by country. Preprints of the International Lightning Detection Conference, 2008 Apr 21-23, Tucson, Arizona. Vantaa: Vaisala Publ.; 2008. pp 14.

2. Ritenour AE, Morton MJ, McManus JG, et al. Lightning injury: a review. Burns 2008;34:585-94.

3. Alyan 0, Ozdemir 0, Tufekcioglu 0, et al. Myocardial injury due to lightning strike. Angiology 2006;57:219-23.

4. American heart association. American heart association guidelines for cardiopulmonary resuscitation and emergency cardiovascular care. Part 10.9. Electric shock and lightning strikes. Circulation 2005;112:154-5.

5. Palmer ABD. Lightning injury causing prolongation of the Q-T interval. Postgrad Med J 1987;63:891-4.

6. McIntyre WF, Simpson CS, Redfearn DP, et al. The lightning heart: a case report and brief review of the cardiovascular complications of lightning injury. Indian Pacing Electrophysiol J 2010;10:429-34.

7. Bolli R, Marbán E. Molecular and cellular mechanisms of myocardial stunning. Physiol Rev 1999;79:609-34.

8. 0'Keefe Gatewood M, Zane RD. Lightning injuries. Emerg Med Clin N Am 2004;22: 369-403.

9. Lichtenberg R, Dries D, Ward K, et al. Cardiovascular effects of lightning strikes. J Am Coll Cardiol 1993;21:531-6.

10. Rivera J, Romero KA, González-Chon 0, et al. Severe stunned myocardium after lightning strike. Crit Care Med 2007;35:280-5.

11. Hayashi M, Yamada H, Agatsuma T, et al. A case of takotsubo-shaped hypokinesis of the left ventricle caused by lightning strike. Int Heart J 2005;46:933-8. 